OPEN ACCESS

Covalent Immobilization of Amino- $\beta$-Cyclodextrins on Glassy Carbon Electrode in Aqueous Media

To cite this article: Karina Silva et al 2019 J. Electrochem. Soc. 166 G75

View the article online for updates and enhancements. 


\title{
Covalent Immobilization of Amino- $\beta$-Cyclodextrins on Glassy Carbon Electrode in Aqueous Media
}

\author{
Karina Silva, ${ }^{1}$ José F. Marco, ${ }^{2}$ and Claudia Yañez ${ }^{1, *, z}$ \\ ${ }^{1}$ Centro de Investigación de Procesos Redox, CIPRex, Facultad de Ciencias Químicas y Farmacéuticas, Universidad \\ de Chile, Santiago, Chile \\ ${ }^{2}$ Instituto de Química Física “Rocasolano”, CSIC, 28006 Madrid, Spain
}

\begin{abstract}
In the present work, the application of the amine electrooxidation method to achieve the grafting of amino $\beta$-cyclodextrins $(\mathrm{CD}$ amines) on glassy carbon electrodes (GCE) in aqueous media has been investigated. The results indicate that the electrooxidation procedure of CD-amines on GCE effects their covalent immobilization without the need of additional linkers or intermediates. Cyclic voltammograms of ferricyanide proved that the immobilized CDs cover at a large extent the GCE surface. This immobilization is due to real grafting and not the result of a weak physisorption interaction. Indeed, the presence of contributions characteristic of amide groups and the absence of peaks typical of amine groups in the XPS N 1s spectra of the modified GCE, support the evidence of the covalent bonding of the CDs to the glassy carbon surface through amide bond formation. Electrochemical experiments demonstrated that ferrocenemethanol and bentazon can be encapsulated within the cavity of the CDs immobilized on GCEs via the formation of inclusion compounds. Overall, the results of the present work show that this simple amine-electrooxidation strategy is suitable to immobilize CDs on glassy carbon surfaces while maintaining their inclusion abilities and, therefore, open the door to design cheap and simple electrochemical sensors for environmental applications.

(C) The Author(s) 2019. Published by ECS. This is an open access article distributed under the terms of the Creative Commons Attribution 4.0 License (CC BY, http://creativecommons.org/licenses/by/4.0/), which permits unrestricted reuse of the work in any medium, provided the original work is properly cited. [DOI: 10.1149/2.0971908jes]

(cc) BY
\end{abstract}

Manuscript submitted March 13, 2019; revised manuscript received April 29, 2019. Published May 15, 2019.

The modification of surfaces with a recognition element capable of interacting specifically with a target analyte is a current important challenge. Although biological molecules such as enzymes, antibodies, DNA, and peptides are used as recognition elements that provide high selectivity, they require purification processes that are both expensive and time consuming. Besides, these biomolecules can also suffer a decrease in their activity due to the denaturation produced by the immobilization on an electrode surface..$^{1-4}$ Non-biological molecular systems with excellent recognition properties can be used to develop less expensive and robust sensors. ${ }^{5-7}$ Among the different receptors, cyclodextrins (CDs) are very important due to their recognition properties. The native $\alpha-, \beta$ - and $\gamma$-cyclodextrins are cyclic macromolecules consisting of six, seven, and eight glucopyranose units, respectively. Their peculiar structure consists of a truncated cone having an inner hydrophobic cavity that can be used for the encapsulation of various guest molecules, feature that has led to propose their use in sensors and in the design of biomimetic systems, supramolecular architectures and molecular machines. ${ }^{8-11}$ In order to obtain a robust and durable immobilization, covalent bonding is preferred. CDs have been covalently immobilized on gold using different methodologies. ${ }^{12-17}$ However, carbon materials are preferred because of their high mechanical stability, good electrical conductivity, wide potential windows and low-cost compared to precious metals. As compared with the gold case, the number of reports of immobilization of CDs on carbon materials is not as high. However, some reports have shown that CDs can be either adsorbed on carbon-based nanomaterials having high surface area and high porosity as activated carbon (AC), ${ }^{18}$ immobilized on the surface of carbon-coated cobalt nanomagnets, ${ }^{19}$ covalently immovilized at single-walled carbon nanotube ${ }^{20}$ or electrochemically deposited as a film on carbon paste. ${ }^{21}$ The grafting of native $\beta$-CDs has been also investigated using glutaraldehyde and 1,4-phenylene diisocyanate as organic linker molecules on $\mathrm{AC},{ }^{22}$ however, this latter procedure is very time-consuming due to the many hours involved in the various steps of mixing.

We are interested in immobilizing CDs on glassy carbon (GC) by covalent grafting in a simple way in order to achieve a strong attachment to the surface and such that the CD cavities are exposed toward the solution. To the best of our knowledge, only one work on the covalent grafting of $\beta C D$ on $\mathrm{GC}$ has been reported previously, ${ }^{23}$ in which ferrocene was used as redox catalyst. In this process, ferrocenium ions are generated, which uptake one electron from the $\beta C D$ monoanion yielding an oxygen centred radical that can react either in solution or with the carbon surface. However, the attached organic layer is thick due probably to a branched growing attributable to the multiple primary and secondary hydroxyl groups present in the $\beta C D$.

A route to graft organic molecules to the carbon surfaces involves the electro-oxidation of amine-containing compounds. Although different methodologies have been described for the grafting of amine compounds on carbon surfaces, ${ }^{24-26}$ including some nonelectrochemical methods (for example, by chemical grafting through a Michael reaction, ${ }^{27}$ or by mechanical polishing), ${ }^{28}$ the electrooxidation of amines has been proved to be an efficient method to obtain a strong attachment to the surface. The grafting by anodic oxidation of amine-containing compounds has been usually carried out in organic media $^{29-32}$ while only a few reports of this reaction in aqueous media have been published. ${ }^{33-36}$ The proposed mechanism involves the generation of radicals, which react with the surface of polished glassy carbon leading to a covalent bond to the surface (Scheme 1). ${ }^{30,37}$

According to a previous study, ${ }^{37}$ this reaction is not observed on HOPG (Highly Oriented Pyrolytic Graphite). Therefore, in the method we want to explore here, the immobilization following Scheme 1 would take place at the plane edge of GC since, as pointed out in Ref. 37, the oxygen-containing functional groups like phenols, quinones, and carboxylic acids present in that edge could have a relevant role in the immobilization process.

In the present work, we have explored the use of the electrochemical oxidation of amines for the grafting of CDs on glassy carbon in aqueous media. The use of aqueous media for surface modification is very convenient because is a green and simple procedure which can expand the possibilities of application of the method. The study is focused on establishing a two-step method which involves an oxidation pre-treatment of the GC surface and the electrochemical oxidation of the amine group of the $\beta C D$ derivatives in aqueous media. We have examined the direct reaction of two amine- $\beta C D$ derivatives

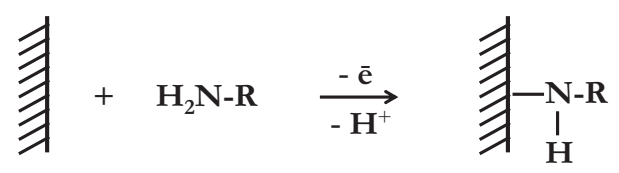

Scheme 1. General mechanism of the electrooxidation of amine-containing compounds. 
containing one and seven amine groups for the modification of the glassy carbon surface. The use of CDs containing a different number of amine groups is aimed at evaluating the role of these groups in the surface grafting as well as in the surface coverage. Cyclic voltammetry has been combined with X-ray Photoelectron Spectroscopy (XPS) to characterize the grafting and determine the nature of the bond with the GC surface. In addition, in order to verify the ability of encapsulating organic molecules into the $\beta C D$ cavities, ferrocenemethanol and bentazon were used. The behavior of both molecules at $\beta C D$ modified electrodes has been previously studied by our group and other researchers $^{38-41}$

\section{Experimental}

Reagents.-6-monodeoxy-6-monoamino- $\beta C D$ (in the following, CD-amine1) and heptakis-(6-amino-6-deoxy)- $\beta C D$ (CD-amine7) were supplied by Ara-Chem and used without prior purification. The redox probes potassium ferricyanide $\left(\mathrm{K}_{3} \mathrm{Fe}(\mathrm{CN})_{6}\right)$ and ferrocenemethanol $(\mathrm{FcOH})$ were obtained from Merck and SigmaAldrich, respectively. Herbicide bentazon was also from SigmaAldrich. All other reagents were of analytical grade. $0.5 \mathrm{M}$ and $2 \mathrm{M} \mathrm{H}_{2} \mathrm{SO}_{4}, 0.1 \mathrm{M} \mathrm{KCl}$ and $0.1 \mathrm{M}$ phosphate buffer, $\mathrm{pH} 5.0$ and 7.0, solutions were used. They were prepared with ultrapure water $(18.2 \mathrm{M} \Omega \mathrm{cm})$ from a Millipore Milli-Q system.

Experimental set-up.-Cyclic voltammograms were recorded using a $\mathrm{CHI} 440(\mathrm{CH}$ Instruments Inc, USA) potentiostat and a $10 \mathrm{~mL}$ home-made electrochemical cell. A glassy carbon electrode (GCE) (3 mm diameter, CHI 104, from CH Instruments Inc.) was used as working electrode. A platinum wire and an $\mathrm{Ag} / \mathrm{AgCl}, 3 \mathrm{M} \mathrm{NaCl}$ electrode (Bioanalytical System, model RE-5B) were used as counter and reference electrodes, respectively. All the potentials are referred to the $\mathrm{Ag} / \mathrm{AgCl}$ electrode.

XPS data were recorded with a Phoibos 150 analyser and nonmonochromatic $\mathrm{Mg} \mathrm{K} \alpha$ radiation under a base pressure better than 5 $\times 10^{-10}$ torr, using a constant pass energy of $100 \mathrm{eV}$ and $20 \mathrm{eV}$ for the wide scan and narrow scan spectra, respectively. The position of the main contribution to the $\mathrm{C} 1 \mathrm{~s}$ spectra $(284.6 \mathrm{eV})$ was used to calibrate the XPS binding energy scale. Relative atomic concentrations were calculated from the peaks area integration after Shirley background subtraction using the Multiquant XPS software ${ }^{42}$

Surface modification.-The surface was modified in two successive steps. First, a pre-treatment of the GC surface was carried out: the electrode was polished with 0.3 and $0.05 \mu \mathrm{m}$ alumina slurries (Buehler) followed by a profuse rinsing with water. The oxidation step consisted of 5 potential cycles between -0.5 and $1.4 \mathrm{~V}$ in $0.5 \mathrm{M}$ $\mathrm{H}_{2} \mathrm{SO}_{4}$ at a scan rate of $0.5 \mathrm{~V} / \mathrm{s}$ followed by holding the GCE at $1.4 \mathrm{~V}$ for $10 \mathrm{~s}$.

Then, in a second step, the electrochemical grafting of the CDamine on the oxidized GCE was carried out by a potential cycle between 0.2 and $1.6 \mathrm{~V}$ in $8 \mathrm{mM} \mathrm{CD}$-amine solutions in phosphate buffer at a scan rate of $50 \mathrm{mV} / \mathrm{s}$. No higher concentrations could be used because of the solubility limit of these CD-amines. All the solutions were degassed with argon prior to the experiments. We used an argon flow during all the procedure instead of a nitrogen flow in order to avoid any contamination which could arise from nitrogen adsorption on the electrode surface. In such a way, we wanted to ensure that no interferences were possible with the nitrogen functionalities of the CDs during the XPS measurements.

Electrochemical behavior on modified surfaces.-The electrochemical response of $1 \mathrm{mM} \mathrm{FcOH}$ in $0.1 \mathrm{M}$ phosphate buffer was studied by cyclic voltammetry at $100 \mathrm{mV} / \mathrm{s}$. FcOH was used instead of ferrocene because of its much higher aqueous solubility.

The electrochemical behavior of various concentrations of bentazon $(20,40,60,80,100,150$ and $200 \mu \mathrm{M})$ prepared in $0.1 \mathrm{M}$ buffer phosphate at $\mathrm{pH} 7.0$ was evaluated by differential pulse voltammetry (DPV). Various tests were carried out using accumulation times be-

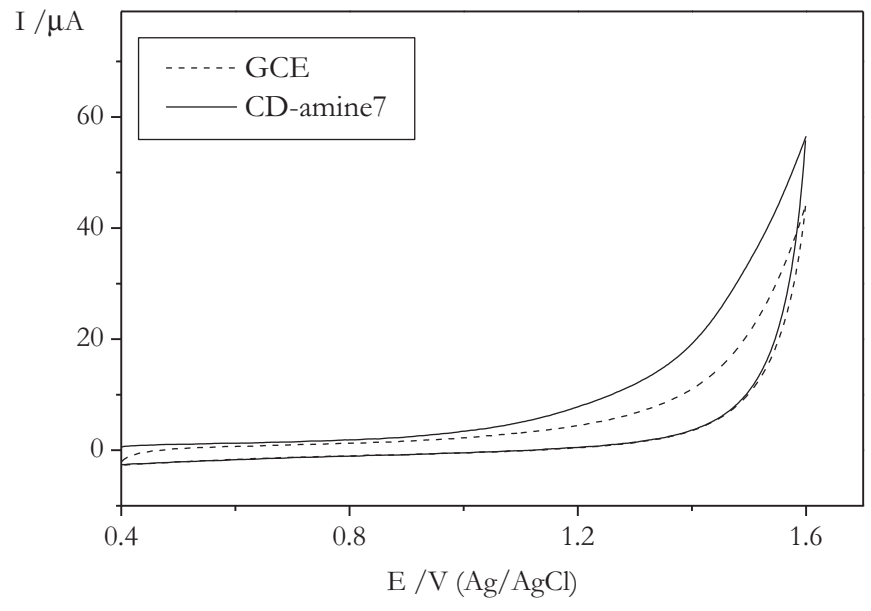

Figure 1. Cyclic voltammograms of clean GCE in $0.1 \mathrm{M}$ phosphate buffer without (dotted line) and with CD-amine7. Scan rate: $50 \mathrm{mV} / \mathrm{s}$.

tween 5 and 25 minutes but very minor changes in current intensity were observed. We decided to use an accumulation time of 10 minutes as we have done in our previous studies with this herbicide. ${ }^{40}$ The potential scan rate, the pulse amplitude and the pulse width used were $20 \mathrm{mV} / \mathrm{s}, 50 \mathrm{mV}$ and $50 \mathrm{~ms}$, respectively. The detection (LOD) and quantitation limits (LOQ) of the method were calculated by using the average and standard deviation of the blank estimated response, the calibration curve slopes and signal/noise ratios of 3 and 10 as is described in Ref. 43.

\section{Results and Discussion}

Grafting of CD-amine on glassy carbon.-To assess the covalent grafting of the CD-amines on the GC surface in aqueous media, we began with the electrochemical oxidation of these amino derivatives on a clean GCE without any binder or linker molecule. We intended to probe the feasibility of immobilizing CD-amine7 on clean GC by applying a positive potential scan. Figure 1 shows that practically no oxidation process was taking place. A similar result was obtained at open circuit (not shown). Because no oxidation wave of CD-amine was observed, the use of oxidized glassy carbon electrode was considered. The oxidation, as described in the Experimental section, produces an increase of the oxygen-containing functional groups on the carbon surface. This issue will be discussed below (XPS characterization).

The grafting procedure was examined both in $0.1 \mathrm{M} \mathrm{KCl}$ and phosphate buffer (pH 5.0 and 7.0) solutions. No acidic media was tested in order to avoid the possible hydrolysis of the CD. For the sake of simplicity, we only show those results obtained in phosphate buffer at $\mathrm{pH}$ 7.0. Figure $2 \mathrm{~A}$ shows the cyclic voltammograms of $8 \mathrm{mM} \mathrm{CD}$-amine1 and $\mathrm{CD}$-amine7 solutions in $0.1 \mathrm{M}$ phosphate buffer using an oxidized $\mathrm{GCE}$ at a scan rate of $50 \mathrm{mV} / \mathrm{s}$. The response of the oxidized $\mathrm{GC}$ in absence of CD-amines is also presented. A broad and irreversible oxidation wave is observed, the oxidation onset being close to 0.8 and $1.0 \mathrm{~V}$ for CD-amine7 and CD-amine1, respectively. This increase of the anodic current from the onset potential to $1.60 \mathrm{~V}$ is similar to that previously reported on the oxidation of alkyl amines on carbon-based electrodes. ${ }^{37}$ Thus, the oxidation wave could be assigned to the oxidation of the amine functionalities of the $\mathrm{CD}$. For the $\mathrm{CD}$-amine1, the charge passed during the first scan is smaller than that measured with the CD-amine7, something which is probably due to the lower amount of amine-groups of the CD-amine1. To increase the anodic charge and, therefore, increase the $\mathrm{CD}$ surface coverage, we attempted to generate more electro-oxidized species on the GCE by cycling the potential twice between $0.5 \mathrm{~V}$ and $1.60 \mathrm{~V}$ in the amine CD-containing solution. This procedure resulted in a significant decrease of the oxidation wave, as it is illustrated for CD-amine 7 (Figure 2B). This decrease of the anodic charge in a second scan is probably due to a passivation 

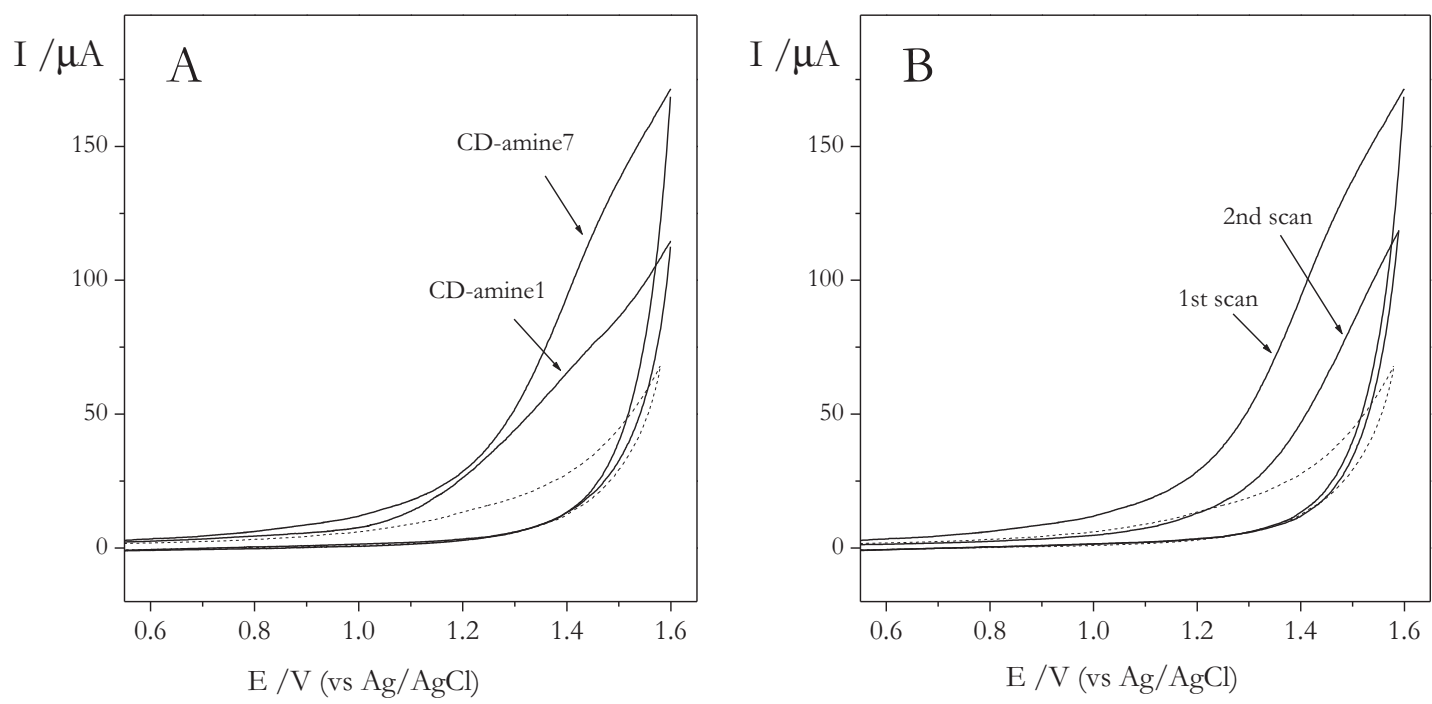

Figure 2. (A) Cyclic voltammograms of CD-amine1 and CD-amine7 (solid scan) on oxidized GCE in $0.1 \mathrm{M}$ phosphate buffer (the dotted lines represent blank solution). (B) Cyclic voltammograms of GCE in $0.1 \mathrm{M}$ phosphate buffer before (dotted line) and after electrooxidation of CD-amine7: first scan (a) and second scan (b). Scan rate: $50 \mathrm{mV} / \mathrm{s}$.

phenomenon. This passivation effect has been previously observed in the electrochemical oxidation of amines ${ }^{30,32}$ and it is attributable to the formation of a coating on the electrode surface which blocks the further oxidation of the amine group. Therefore, it is related to the grafting of the amine-containing molecule to the electrode surface.

Although the electrochemical bonding/passivation has been reported for amines in organic and aqueous media, ${ }^{30,32,35}$ we have considered to examine the behavior of amine-containing compounds (other than CDs) in the same conditions used in this work. Thus, we have performed electrochemical experiments at oxidized GCE using ethylene diamine in $0.1 \mathrm{M}$ phosphate buffer at $\mathrm{pH}$ 7.0. The results are collected in Figure 3. At ethylene diamine concentrations comparable to that of CD-amine1 and CD-amine $7(8 \mathrm{mM})$, an increase in the anodic current is observed during the first scan together with a decrease in the anodic charge during the second scan (Figure 3, curve a and a'), very similarly to that observed with the CD-amines. We have also tested different ethylene diamine concentrations (Figure 3, curve b and c). In these tests, the oxidation charge increases, a noticeable peak current is observed at $1.22 \mathrm{~V}$, and the onset potential is slightly shifted to less positive values with increasing ethylene diamine concentration in the solution. These results are, then, compatible with the electrochemical oxidation of amines during the first scan and with the passivation effect of the electrode during the second scan, as reported previously, ${ }^{30,32,35}$ and support the electrochemical oxidation of the amine functionality of the CD.

The grafting of amine-CD at the oxidized GCE surface was further studied by comparing the cyclic voltammogram of the bare and modified electrodes using potassium ferricyanide as redox mediator. Since ferricyanide ion does not form inclusion complexes with $\beta C D$, we have used it to characterize the macrocycle-modified surfaces. ${ }^{38,39}$ Thus, the variations on the electrochemical response of the redox mediator at the modified surface can be indirectly associated with the CD coverage. ${ }^{17,38}$ Figure 4 shows the cyclic voltammograms of potassium ferricyanide in $0.1 \mathrm{M}$ phosphate buffer, $\mathrm{pH} 7.0$, on both bare and $\mathrm{CD}$ amine modified GCEs. A reversible electron transfer process of the redox mediator is observed on the bare GCE with a cathodic (Epc) and anodic (Epa) peak separation, $\Delta \mathrm{Ep}=(68 \pm 3) \mathrm{mV}$. The cyclic voltammograms show a decrease of the current density together with an increase in $\Delta \mathrm{Ep}$ to $(270 \pm 9)$ and $(310 \pm 8) \mathrm{mV}$ for GC/CD-amine 7 and GC/CD-amine1, respectively. As mentioned before, ferricyanide does not form inclusion complexes with the $\beta$-CDs, so the electron transfer between the redox probe and the electrode surface can be partially inhibited by the cyclodextrin derivatives immobilized on the GC surface. As we have reported in our previous work on the immobiliza- tion of CDs on gold, ${ }^{17}$ this behavior of the redox mediator could be associated with a partial CD surface coverage or with the formation of a CD thin layer- Thus, the ferricyanide electron transfer reaction would take place even through the CD barrier in an analogous manner as that observed by Kubota et al. in a monolayer of short-chain thiols chemimisorbed on gold. ${ }^{44}$ For the GC/CD-amine modified surfaces, we determined the hindrance (B) in order to quantify the layer density. We used procedures previously described ${ }^{38,45}$ where the ratio of the reduction peak of ferricyanide measured at both the modified (Ipc (CD)) and the bare (Ipc (GCE)) electrode are considered. Taking this

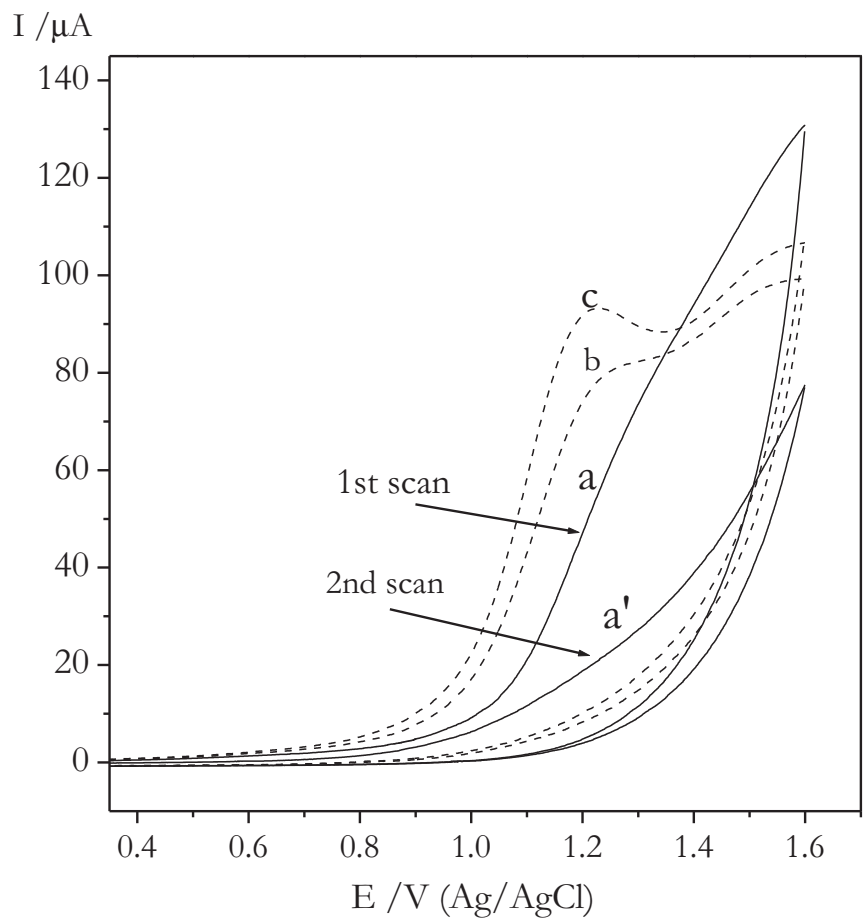

Figure 3. Cyclic voltammograms of $8 \mathrm{mM}$ ethylene diamine on GCE in $0.1 \mathrm{M}$ phosphate, first scan (a) and second scan (a'). Cyclic voltammograms of $15 \mathrm{mM}$ (b) and $30 \mathrm{mM}$ (c) ethylene diamine on GCE in $0.1 \mathrm{M}$ phosphate. Scan rate: $50 \mathrm{mV} / \mathrm{s}$. 


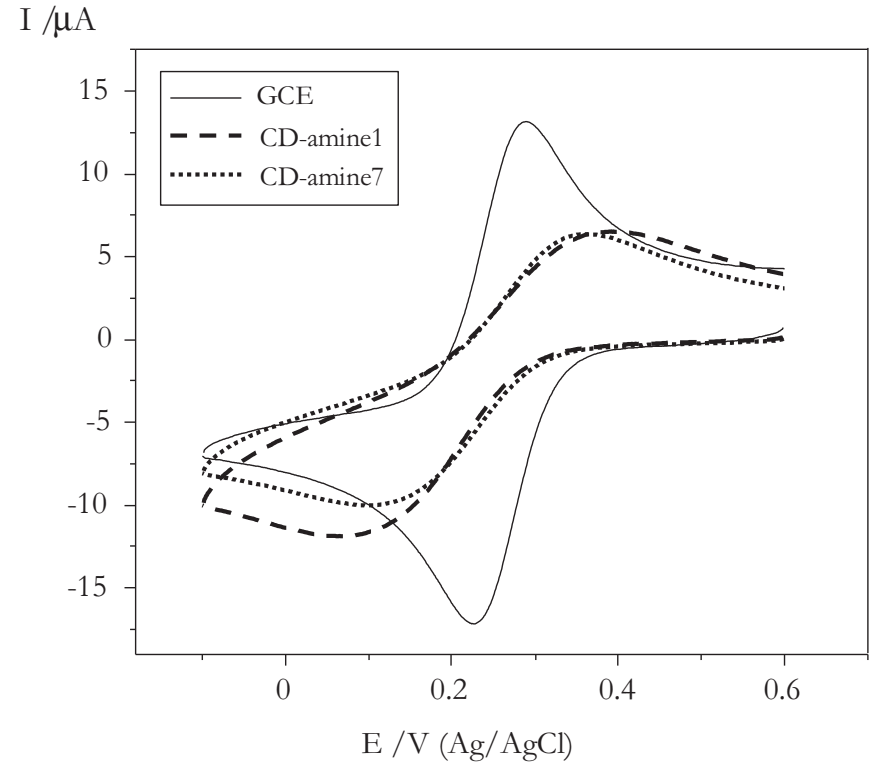

Figure 4. Cyclic voltammograms obtained in $1.0 \mathrm{mM} \mathrm{K}_{3}\left[\mathrm{Fe}(\mathrm{CN})_{6}\right]$ in $0.1 \mathrm{M}$ phosphate buffer solution $\mathrm{pH} 7.0$ on bare GCE (solid line); GC/CD-amine1 (dashed line) and GC/CD-amine7 (dotted line). Scan rate; $100 \mathrm{mV} / \mathrm{s}$.

into account, the hindrance can be expressed as:

$$
\mathrm{B}=1-[\mathrm{Ipc}(\mathrm{CD}) / \mathrm{Ip}(\mathrm{GCE})]
$$

Values of 39 and $42 \%$ were obtained for GC/CD-amine1, GC/CDamine7, respectively. These values are much higher than those obtained for CD immobilized on gold. ${ }^{17}$ The calculated $\mathrm{B}$ values and the cyclic voltammograms of the modified electrodes (Fig. 2A), suggest that a slightly more compact layer is obtained for GC/CD-amine7 than for GC/CD-amine1. However, we were unable to obtain any experimental evidence concerning the number of $\mathrm{CD}$-amines attached to the surface.

Stability of the grafting of CD-amines.-To confirm that this attachment is due to real grafting and not to physorption we have carried out several tests where the modified electrodes were: (i) profusely rinsed with water and subsequently with ethanol; (ii) immersed in hot water $\left(\sim 70^{\circ} \mathrm{C}\right)$; (iii) sonicated in water for 10 minutes, (iv) immersed in $2 \mathrm{M} \mathrm{H}_{2} \mathrm{SO}_{4}$ for 10 minutes. After each one of these procedures we have recorded the corresponding voltammograms of ferricyanide in $0.1 \mathrm{M}$ phosphate buffer, pH 7.0. For evaluating the surfaces after the tests, ferricyanide was used as redox probe. The results for GC/CD-amine1 are presented in Figure 5 (the same results were obtained for GC/CDamine7). After the tests, the cyclic voltammograms show very little variation as compared with the GC/CD-amine1 modified electrode, except in the case of the treatment in $\mathrm{H}_{2} \mathrm{SO}_{4}$ where the voltammogram shows an intermediate situation between that of the bare GCE and that of the GC/CD-amine1. The behavior of the modified surfaces remained stable after two months (this stability was determined considering that the $\mathrm{CD}$ grafted on the electrodes can still block the electrochemical reaction of ferricyanide in the same way). The behavior of the surface was very persistent and could only be reversed by a mechanical polish of the electrode. Taken together, the results would discard the occurrence of physisorption and support the covalent attachment of CD-amines on the GC surface. For the particular case of $\mathrm{H}_{2} \mathrm{SO}_{4}$, it appears that the results would be due not only to the removal of the CD-amines from the GC surface but also to the destruction of the cyclodextrin structure itself resulting from the hydrolysis of the $\alpha-1,4$ glycosidic bonds in a such strong acid solution. ${ }^{46}$

X-Ray photoelectron spectra (XPS) characterization.-In order to obtain a chemical insight of the interactions occurring between the

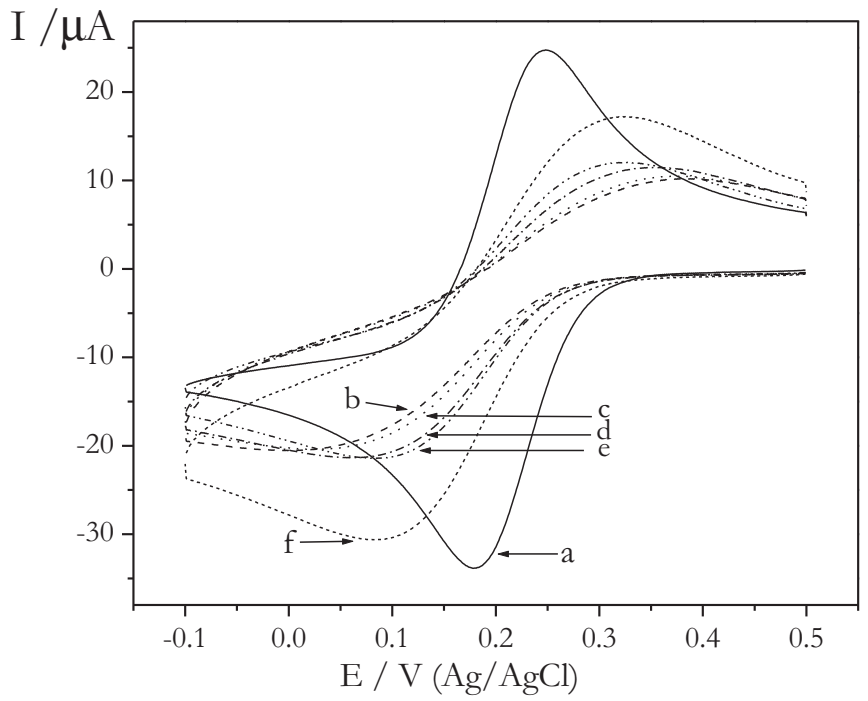

Figure 5. Cyclic voltammograms obtained in $1.0 \mathrm{mM} \mathrm{K}_{3}\left[\mathrm{Fe}(\mathrm{CN})_{6}\right]$ in $0.1 \mathrm{M}$ phosphate buffer solution $\mathrm{pH} 7.0$ on bare GCE (a, solid line); GC/CD-amine1 (b, dashed line) and after GC/CD-amine1 was rinsed with water and subsequently with ethanol (c, dotted line), rinsed with hot water (d, dash dot line), sonicated in water for 10 minutes (e, dash dot dot line) and immersed in $2 \mathrm{M}$ $\mathrm{H}_{2} \mathrm{SO}_{4}$ for 10 minutes (f, short dash line). Scan rate $=100 \mathrm{mV} / \mathrm{s}$.

CD-amine layers and the GC surface, XPS measurements were performed. The XPS wide scan spectra recorded from the different samples are dominated by a very intense carbon signal and a relatively intense oxygen signal. The presence of oxygen in the clean GC is usual and corresponds to various moieties which can be present on its surface. The electrochemical oxidation of the clean GCE brings about a significant increase in oxygen concentration $(7.0 \%$ in the clean GCE vs. $21.8 \%$ in the oxidized GCE). The GC/CD-amine surfaces also display a much more important oxygen contribution than the clean GCE although it is, in both cases, slightly smaller than in the oxidized GCE (17.0\% and $17.7 \%$ for GC/CD-amine1 and GC/CD-amine7, respectively). In the case of the clean GCE, the presence of a very minor nitrogen signal (traces), of difficult quantification, was observed. The presence of nitrogen traces on the surface of clean GCEs is not unusual and, in fact, has been reported in numerous occasions. ${ }^{37,47}$ The spectra recorded from the GC/CD-amine surfaces show an identifiable and measurable nitrogen signal $(1.6 \%$ and $3.4 \%$ for GC/CD-amine 1 and GC/CD-amine7, respectively).

The high resolution $\mathrm{C} 1 \mathrm{~s}$ spectra recorded from the various samples are shown in Figure 6. The C 1s spectra of the clean GCE contains four different contributions, which appear also in the rest of the samples but with different intensities. Their binding energies, $284.6 \mathrm{eV}$, 285.8-286.0 eV, 287.0-287.5 eV and 288.6-288.9 eV are very similar to those reported previously in similar samples ${ }^{48-50}$ and can be assigned to graphitic/aliphatic-type groups $(\mathrm{C}-\mathrm{C}$ or $\mathrm{C}-\mathrm{H})$, phenolic-type groups $(\mathrm{C}-\mathrm{N}$ or $\mathrm{C}-\mathrm{O})$, carbonyl-type groups $(\mathrm{C}=\mathrm{O}, \mathrm{O}-\mathrm{C}-\mathrm{O}, \mathrm{N}-\mathrm{C}=\mathrm{O})$ and carboxyl-type groups $(\mathrm{C}-\mathrm{O}-\mathrm{C}=\mathrm{O}, \mathrm{HO}-\mathrm{C}=\mathrm{O})$, respectively. It is interesting to note that in the oxidized GCE the contributions due to carbonyl-type and carboxyl-type groups increase significantly, from $10 \%$ in total in the clean GCE to $24 \%$ in the oxidized GCE (Figures $6 \mathrm{a}$ y $6 b)$. The $\mathrm{C} 1 \mathrm{~s}$ spectra recorded from the $\mathrm{GC} / \mathrm{CD}$-amine samples are very similar to that reported for a $\beta-C D$ film. ${ }^{50}$ In this respect, it is interesting to note, especially in the GC/CD-amine7 (Figure 6d), the increasing importance of the contributions characteristic of C-O (19\% and $22 \%$ for GC/CD-amine 1 and GC/CD-amine7, respectively) and $\mathrm{N}-\mathrm{C}=\mathrm{O}$ groups $(8 \%$ and $16 \%$ for $\mathrm{GC} / \mathrm{CD}$-amine 1 and $\mathrm{GC} / \mathrm{CD}$-amine 7 , respectively) as compared with the $13 \%(\mathrm{C}-\mathrm{O})$ and $6 \%(\mathrm{C}=\mathrm{O}, \mathrm{O}-\mathrm{C}-\mathrm{O}$, $\mathrm{N}-\mathrm{C}=\mathrm{O}$ ) of the clean GCE. However, in the present case, the intensity of the main peak, due to aliphatic or graphitic carbon, is higher than that reported in Ref. 50 This could indicate that, in the samples 


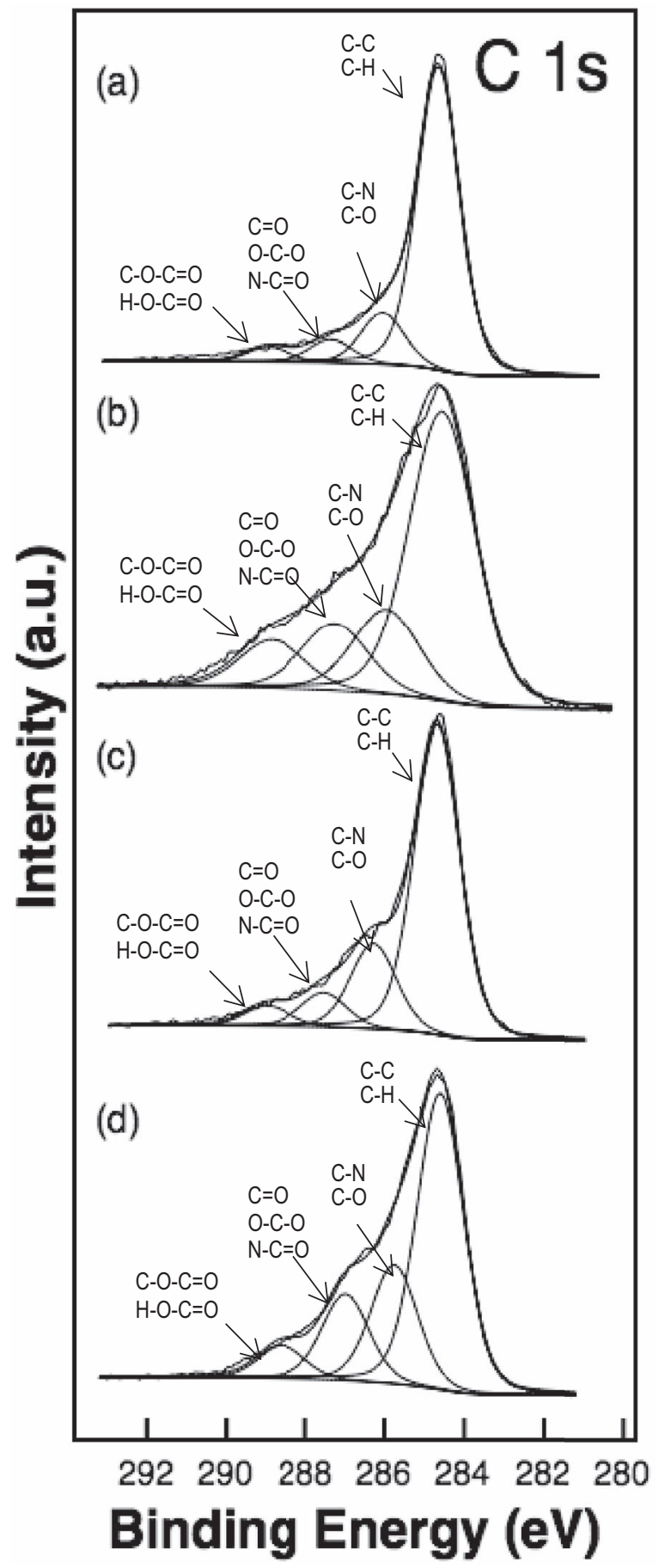

Figure 6. C 1s XPS spectra of the various samples: (a) clean GC, (b) oxidized GC, (c) CD-amine1, (d) CD-amine7.

reported in our paper, there is still some contribution from the GCE due to a partial coverage of the $\mathrm{CD}$-amine on $\mathrm{GC}$ surface.

Figure 7 shows the $\mathrm{N}$ 1s spectra recorded from the GC/CD-amine surfaces. The major contribution, accounting for $86-89 \%$ of the spectral area, appears at around $400.1 \mathrm{eV}$. It is quite well established that amine groups are characterized by binding energies of the $\mathrm{N} 1 \mathrm{~s}$ core level of 398.5-399.4 eV while the $\mathrm{N} 1 \mathrm{~s}$ binding energies associated to amide groups are higher and lie within $400.0-400.3 \mathrm{eV} .^{27,37,50-53}$ Therefore, the main nitrogen signal in the CD-amine modified GC surface could correspond to amide nitrogen. We would like to mention that some reports ${ }^{34,35}$ claim the formation of carbon-nitrogen bonds, pro-

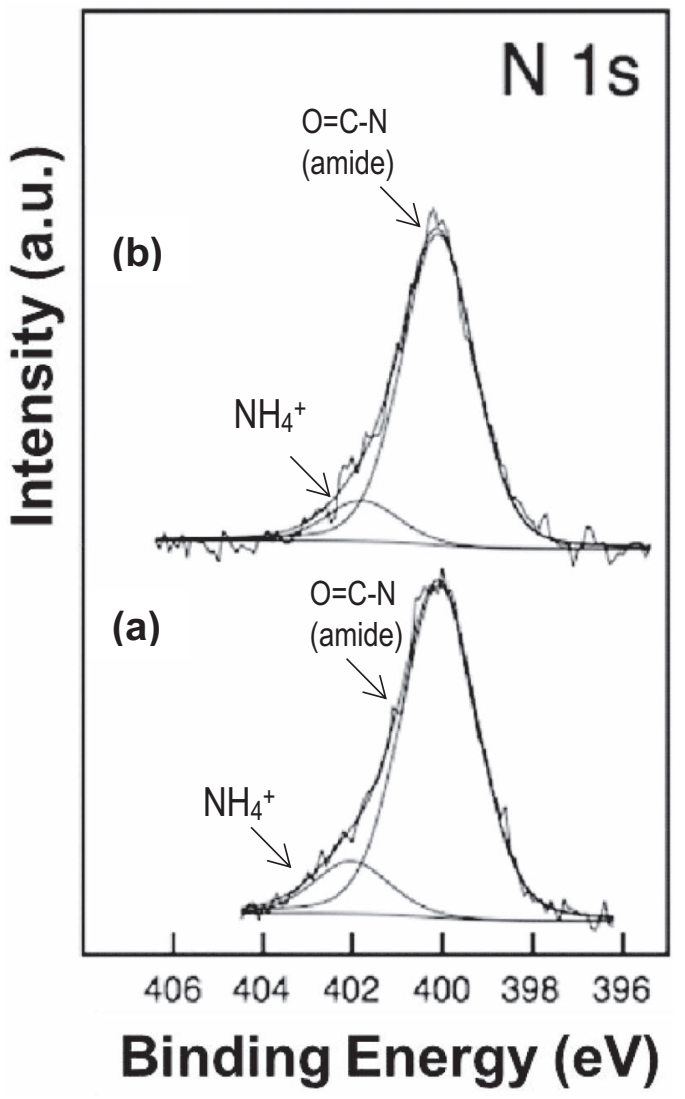

Figure 7. N 1s XPS spectra of the various samples (a) CD-amine1, (b) CDamine7.

duced by electro-grafting of amine compounds on carbon electrodes in aqueous media, based on the presence in the corresponding $\mathrm{N} \mathrm{1s}$ spectra of contributions located at 399.6 and $399.9 \mathrm{eV}$. However, in these works there is no clear information on the calibration of the binding energy scale, what precludes a direct comparison with the values observed in our work. In any case, we think that the results found in the present study are a clear indication of the formation of a $\mathrm{N}-\mathrm{C}$ bond to oxygen-containing functional groups $(\mathrm{C}=\mathrm{O})$ at the $\mathrm{GC}$ surface, although the details of the mechanism remain unclear. The spectrum shows a second minor contribution at $402.0 \mathrm{eV}(11-14 \%)$ that could correspond to a quaternary ammonium nitrogen species. ${ }^{54}$ Although the origin of this nitrogen species is not clear, we would like to mention that it has been also observed in the XPS of other $\beta$ cyclodextrin films ${ }^{50}$ It is worth mentioning that the data recorded from the GC/CD-amine7 show a larger nitrogen contribution than those of the $\mathrm{GC} / \mathrm{CD}$-amine 1 as well as more intense $\mathrm{N}-\mathrm{C}=\mathrm{O}$ contributions (see above) indicating, again, that they have been successfully attached to the carbon surface.

Comparison of the voltammograms in Figure 2A, where the anodic current observed for GC/CD-amine7 is somewhat higher than for GC/CD-amine1 together with the calculated B values, suggest that the surface coverage by the $\mathrm{CD}$-amine 7 is slightly higher. The larger nitrogen concentration found in XPS for GC/CD-amine7 must result from the combination of both a larger number of nitrogen groups present in this cyclodextrin and the higher coverage observed in this latter case, since both contributions cannot be easily disentangled. In any case, this is, indeed, an additional proof that the grafting process used to modify the GC surface is effective to attach the CD-amines to the surface.

Behavior of the modified surface.-To investigate whether the abilities of $\mathrm{CD}$ to form inclusion complexes have not been affected 


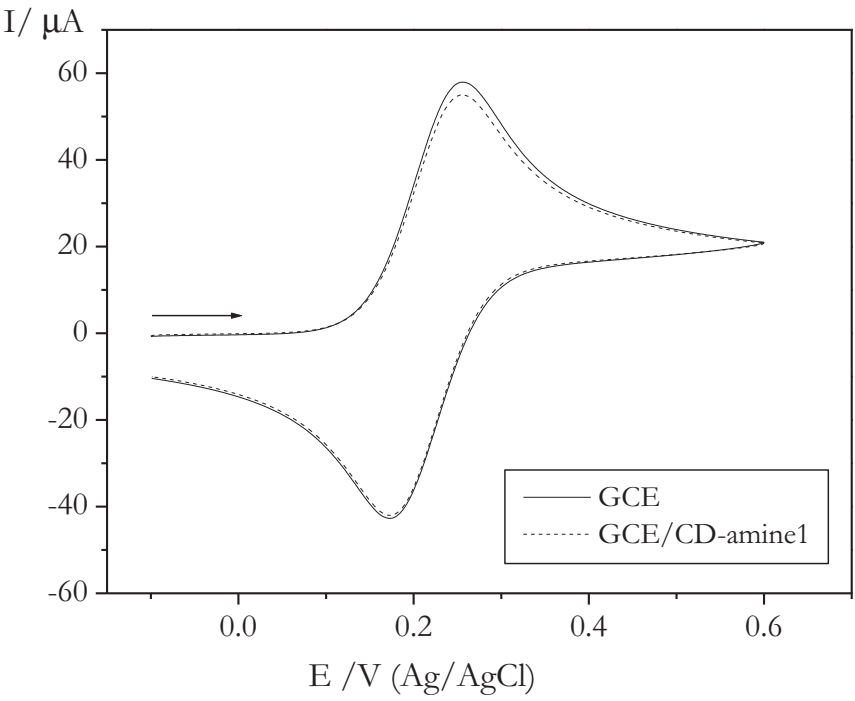

Figure 8. Cyclic voltammograms obtained in $1.0 \mathrm{mM} \mathrm{FcOH}$ in $0.1 \mathrm{M}$ phosphate buffer solution pH 7.0 on bare GCE (solid line) and GC/CD-amine1 (dashed line).

by the grafting procedure, we have evaluated their behavior using ferrocene-methanol $(\mathrm{FcOH})$ and bentazone $(\mathrm{Btz})$. Both molecules are able to fit into the $\mathrm{CD}$ cavity. ${ }^{38-41}$ Figure 8 shows the cyclic voltammograms of $1.0 \mathrm{mM} \mathrm{FcOH}$ in $0.1 \mathrm{M} \mathrm{pH} 7.0$ phosphate buffer on bare GCE and modified GCE/CD-amine1. The electrochemical mechanism involves a one-electron-transfer step. ${ }^{55}$ No differences were observed respect to the CVs of bare GCE: oxidation and reduction potentials remained constant, and only a negligible decrease of the peak currents was observed. As expected, the grafting procedure of CD-amine on the GC surface did not hinder the redox process of $\mathrm{FcOH}$, since this undergoes encapsulation in the $\beta C D$ cavity (the association constant of the ferrocene/ $\beta C D$ inclusion complex in aqueous media is close to 1.65 $\left.\times 10^{4} \mathrm{M}^{-1}\right),{ }^{56}$ thereby having nearly direct access to the GC surface. We also have tested the ability of the grafted CD-amine to form inclusion complexes with the herbicide bentazon. $\beta C D$ modified electrodes have been used to determine Btz taking advantage of the formation of inclusion complexes with CDs. ${ }^{41}$ In this case, we have used differential pulse voltammetry (DPV). ${ }^{40}$ Figure 9 shows the DPV recorded from different bentazon concentrations on bare GCE (Fig. 9A) and on GCE/CD-amine7 in buffer phosphate (Fig. 9B). In the former, the voltammograms show broad, ill-defined peaks whose maxima shift to higher potentials as Btz concentration increases. This behavior has been previously observed. ${ }^{41,57}$ According these reports, the electrooxidation mechanism of Btz at GCE involves an electrochemical step followed by a chemical dimerization reaction of the products, which are strongly adsorbed on the electrode surface causing poisoning of the surface.

When the modified electrode is used, the peaks are very welldefined, they do not shift with applied potential and appear at slightly higher potential than on GCE. This is a clear indication that, in the case of the modified electrodes, the electron transfer reaction occurs through the CD cavities and, with all likelihood, an inclusion complex is being formed what requires a short additional potential. The response of Btz on modified GC surfaces exhibited a linear behavior in the range from 20 to $200 \mu \mathrm{M}$ (Figure 10). Interestingly, in the case of Btz, the current intensity on GC/CD-amine7 is slightly higher than GC/CD-amine1, an effect that, for the same accumulation time $(10 \mathrm{sec})$ is more noticeable at high Btz concentrations. For Btz, the formation of an inclusion complex where the electroactive moiety of the molecule is located outside the cavity while the benzene ring is oriented toward the CD cavity, has been previously suggested. ${ }^{58,59}$ Thus, we can assume that the observed behavior would arise from the combination of the inclusion complex structure together with the fact that the GC/CD-
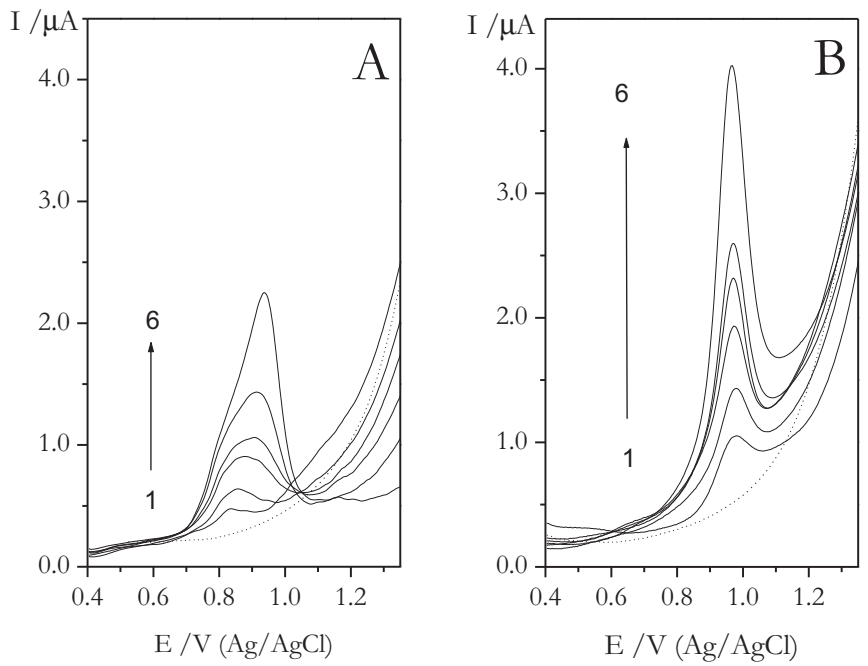

Figure 9. Differential pulse voltammetry curves for bentazon on bare GCE (A) and GCE/CD-amine7 (B) in $0.1 \mathrm{M}$ phosphate buffer, $\mathrm{pH} 7.0$ using an accumulation time of 10 minutes. Bentazon concentrations employed 20, 40, $60,80,100,200 \mu \mathrm{M}$ (numbered from 1 to 6 , respectively).

amine7 system would form a slightly more compact layer (B values of 39 and $42 \%$ for GC/CD-amine 1 and GC/CD-amine7, respectively) favoring the inclusion of more Btz molecules in the GC/CD-amine7 electrode. The calibration curves were described by the following regression equations: $\mathrm{Ip}[\mu \mathrm{A}]=0.0199[\mu \mathrm{A} / \mu \mathrm{M}] \times \mathrm{C}[\mu \mathrm{M}]+0.1379$ $[\mu \mathrm{A}](\mathrm{r}=0.9993) ; \mathrm{Ip}[\mu \mathrm{A}]=0.0142[\mu \mathrm{A} / \mu \mathrm{M}] \times \mathrm{C}[\mu \mathrm{M}]+0.11069$ $[\mu \mathrm{A}](\mathrm{r}=0.9979) ; \mathrm{Ip}[\mu \mathrm{A}]=0.0098[\mu \mathrm{A} / \mu \mathrm{M}] \times \mathrm{C}[\mu \mathrm{M}]+0.0344$ $[\mu \mathrm{A}](\mathrm{r}=0.9961)$ for $\mathrm{GC} / \mathrm{CD}$-amine7, GC/CD-amine1 and GCE, respectively. The limit of detection (LOD), obtained from five runs, were 2.4, 2.9 and $8.7 \mu \mathrm{M}$ and the limit of quantification (LOQ) were 3.8, 4.5 and 14.3 $\mu \mathrm{M}$ for GC/CD-amine7, GC/CD-amine 1 and GCE, respectively. Intra-day and inter-day reproducibilities (RSD\%) were lower than $5.0 \%$ for GC/CD-amine7 and GC/CD-amine1. RSD values of $9.2 \%$ were obtained for GCE. LOD values obtained in this work are slightly higher than other reported for modified electrodes, for example, a PANI- $\beta$-CD/fMWCNT/GC modified electrode showed a LOD of $1.6 \mu \mathrm{M}^{41}$ Even lower LOD values were obtained with a

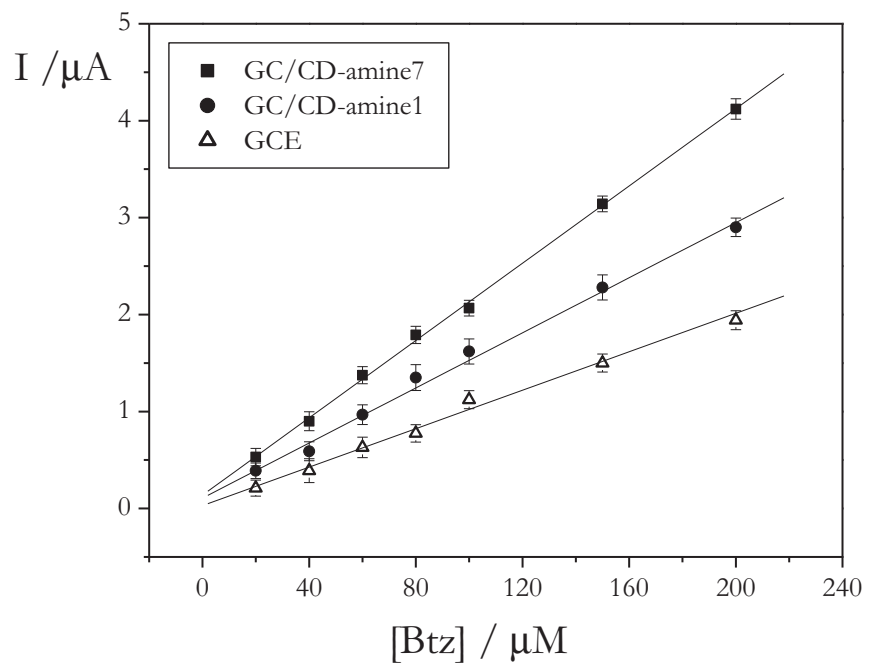

Figure 10. Peak current intensity (Ip) versus bentazon concentration for $\operatorname{GCE}(\Delta)$, GC/CD-amine1 $(\bullet)$ and GC/CD-amine7 (.). Ip values were determined from differential pulse voltammetry curves for bentazon on bare GCE, GCE/CD-amine7 and GCE/CD-amine1 in $0.1 \mathrm{M}$ phosphate buffer, $\mathrm{pH} 7.0$ using an accumulation time of 10 minutes. 
boron-doped diamond electrode (LOD of $0.5 \mu \mathrm{M}),{ }^{60}$ although this one is an unmodified electrode. For bare GCE, a LOD value of $10^{-5} \mathrm{M}$ has been reported. ${ }^{57}$ Although the LOD values obtained by us are no showing improved results as compared with other reported methods, the larger currents measured at low bentazon concentrations on the CD.amine modified surfaces as compared with those observed on GCE, indicate that the former have a larger sensitivity for bentazon detection (sensitivity of 19.9 and $14.2 \mu \mathrm{A} \mathrm{mM}{ }^{-1}$ for GC/CDamine7 and GC/CD-amine1, respectively; for GCE the sensitivity is $9.9 \mu \mathrm{A} \mathrm{mM}^{-1}$ ). The proposed method is simple and shows an improved response when compared with bare GCE. Besides, no significantly high current intensities were expected taking into account the association constant, $\mathrm{K}_{\mathrm{a}}$, of the Btz/ $\beta \mathrm{CD}$ obtained in aqueous media by DPV $\left(\mathrm{K}_{\mathrm{a}}=118 \mathrm{M}^{-1}\right)$. ${ }^{61}$ The use of these modified surfaces for the determination of analytes with higher association constants will be investigated in ongoing studies.

\section{Conclusions}

We have reported a method to immobilize CD-amines on oxidized GC substrates by means of the electrochemical oxidation of the amine group of the CD in aqueous media. The data presented in the paper indicate that $C D$-amines reach a significant coverage of the electrode surface and that they are strongly attached (and not weakly physisorbed) to the substrate, most probably, as the XPS data indicate, by means of covalent bonding through amide bond formation. The electrochemical results concerning the encapsulation of ferrocenemethanol and bentazon showed that the inclusion abilities of the immobilized CD are maintained. Thus, this method proves useful to prepare in an easy way CD modified-GCEs, in which the inclusion abilities could be exploited.

\section{Acknowledgments}

The authors acknowledge financial support from FONDECYT (Grant. N. 1151329) and MINECO, Spain (Project MAT2015-64110C2-1-P).

\section{ORCID}

Claudia Yañez (1D https://orcid.org/0000-0003-4531-0742

\section{References}

1. J. J. Gooding, Anal. Chim. Acta, 559, 137 (2006).

2. J. Kirsch, C. Siltanen, Q. Zhou, A. Revzin, and A. Simonian, Chem. Soc. Rev., 42 8733 (2013).

3. J. Liu, LF. Yin, Y. R. Dai, F. Jiang, and J. F. Niu, Prog. Chem., 24, 131 (2012).

4. R. Fogel and J. L. Limson, Enzyme Microb. Tech., 49, 153 (2011).

5. M. Inclán, M. T. Albelda, E. Carbonell, S. Blasco, A. Bauza, A. Frontera, and E. García-España, Chem-Eur. J., 20, 3730 (2014).

6. D. Z. Jiao, F. Biedermann, F. Tian, and O. A. Scherman, J. Am. Chem. Soc., 132 15734 (2010)

7. T. Ogoshi and T-A. Yamagishi, Eur. J. Org. Chem., 15, 2961 (2013).

8. L. García-Río, FJ. Otero-Espinar, A. Luzardo-Álvarez, and J. Blanco-Méndez, Curr. Top. Med. Chem., 14, 478 (2014).

9. B. V. K. J. Schmidt, M. Hetzer, Helmut Ritter, and C. Barner-Kowollik, Prog. Polym Sci., 39, 235 (2014)

10. Z. Luo, X. W. Ding, Y. Hu, S. J. Wu, Y. Xiang, Y. F. Zeng, B. L. Zhang, H. Yan, H. C. Zhang, L. L. Zhu, J. J. Liu, J. H. Li, K. Y. Cai, and Y. L. Zhao, ACS Nano, 7, $10271(2013)$

11. B. V. K. J. Schmidt and C. Barner-Kowollik, Polym. Chem-UK, 5, 2461 (2014).

12. G. Nelles, M. Weisser, R. Back, P. Wohlfart, G. Wenz, and S. Mittler-Neher, J. Am. Chem. Soc., 118, 5039 (1996).
13. M. T. Rojas, R. Koniger, J. F. Stoddart, and A. E. Kaifer, J. Am. Chem. Soc., 117, 336 (1995).

14. A. E. Kaifer and M. Gomez-Kaifer, Supramolecular Electrochemistry: SelfAssembled Monolayers, Wiley-VCH, Weinheim, 1999 chapter 15.

15. J. M. Campiña, A. Martins, and F. Silva, Electrochim. Acta, 55, 90 (2009)

16. A. Méndez-Ardoy, T. Steentjes, T. Kudernac, and J. Huskens, Langmuir, 30, 3467 (2014).

17. M. García, S. Bollo, G. A. Rivas, N. F. Ferreyra, and C. Yañez, Electrochim. Acta, 203, 292 (2016).

18. N. Kania, S. Rio, E. Monflier, and A. Ponchel, J. Colloid and Interface Sci., 371, 89 (2012).

19. R. Fuhrer, I. K. Herrmann, E. K. Athanassiou, R. N. Grass, and W. J. Stark, Langmuir, 27, 1924 (2011).

20. Y. Gao, Y. Cao, G. Song, Y. Tang, and H. Li, J Biomater Nanobiotechnol, 2, 454 (2011).

21. G. Roa-Morales, T. Ramírez Silva, and L. Galicia, J. Solid State Electrochem., 7, 355 (2003).

22. J. H. Kwon and L. D. Wilson, J Environ Sci Health Part A, 45, 1775 (2010)

23. L. S. Hernández-Muñoz, C. Frontana, and F. J. González, Electrochim. Acta, 138, 22 (2014).

24. A. J. Downard, Electroanalysis, 12, 1085 (2000)

25. D. Bélanger and J. Pinson, Chem. Soc. Rev., 40, 3995 (2011).

26. L. Lee and A. J. Downard, J Solid State Electrochem, 18, 3369 (2014).

27. D. A. Buttry, J. C. M. Peng, J.-B. Donnet, and S. Rebouillat, Carbon, 37, 1929 (1999).

28. A. Anne, B. Blanc, J. Moiroux, and J -M. Savéant, Langmuir, 14, 2368 (1998).

29. A. Adenier, M. M. Chehimi, I. Gallardo, J. Pinson, and N. Vilà, Langmuir, 20, 8243 (2004).

30. B. Barbier, J. Pinson, G. Desarmot, and M. Sanchez, J. Electrochem. Soc., 137, 1757 (1990).

31. H. Jarrar, M. Rolland, A. J. Downard, and M. Cretin, Sensor Lett., 9, 2368 (2011).

32. A. J. Downard and A. Mohamed, Electroanalysis, 11, 418 (1999).

33. F. Geneste and C. Moinet, New J. Chem., 29, 269 (2005).

34. G. Yang, B. Liu, and S. Dong, J. Electroanal. Chem., 585, 301 (2005).

35. G. Yang, Y. Shen, M. Wang, H. Chen, B. Liu, and S. Dong, Talanta, 68, 741 (2006).

36. T. H. Kim, H. S. Choi, B. R. Go, and J. Kim, Electrochem. Comm., 12, 788 (2010).

37. R. S. Deinhammer, M. Ho, J. W. Anderegg, and M. D. Porter, Langmiur, 10, 1306 (1994).

38. S. Bollo, C. Yáñez, J. Sturm, L. Núñez-Vergara, and J. A. Squella, Langmuir. 19, 3365 (2003).

39. F. S. Damos, R. C.S.Luz, and L. T. Kubota, Electrochim. Acta, 53, 1945 (2007)

40. A. M. Méndez-Torres, C. Sandoval-Altamirano, M. Sanchez-Arenillas, J. F. Marco, and C. Yáñez, Electrochim. Acta, 282, 860 (2018).

41. V. Rahemi, J. M. P. J. Garrido, F. Borges, C. M. A. Brett, and E. M. P. J. Garrido, Electroanalysis, 25, 2360 (2013).

42. M. Mohai, Surf. Interf. Anal., 36, 828 (2004)

43. O. Quattrocchi, S. De Andrizzi, and R. Laba, Introduccion a la HPLC, Aplicación y práctica, Artes Gráficas Farro S.A.,Buenos Aires. Argentina 1992, ch. 12, pp. 321

44. R. K. Mendes, R. S. Freire, C. P. Fonseca, S. Neves, and L. T. Kubota, J. Braz. Chem. Soc., 15, 849 (2004).

45. M. Weisser, G. Nelles, P. Wohlfart, G. Wenz, and S. Mittler-Neher, J. Phys. Chem., 100, 17893 (1996).

46. R. Vaitkus, G. Grimciene, and E. Norkus, J. Incl. Phenom. Macrocycl. Chem., 69, 345 (2011).

47. G-P. Yin, X-Q. Lin, and J. Gong, J. Electroanal. Chem., 569, 135 (2004).

48. G. N. Raman, W. S. Willis, and J. F. Rusling, Anal. Chem., 57, 545 (1985).

49. A. Dekanski, J. Stevanovic, R. Stevanovic, B. Z. Nikolic, and V. M. Jovanovic, Carbon, 39, 1195 (2001)

50. N. Kistamah, C. M. Carr, and S. Rosunee, Surf. Interf. Anal., 41, 710 (2009).

51. N. Graf, E. Yegen, T. Gross, A. Lippitz, W. Weigel, S. Krakert, A. Terfort, and W. E. S. Unger, Surf. Sci, 603, 2849 (2009).

52. T. R. Gengebach, R. C. Chatelier, and H. J. Griesser, Surf. Interf. Anal., 24, 611 (1996).

53. O. Olivares, N. V. Likhanova, G. Gómez, J. Navarrete, M. E. Llanos-Serrano, E. harce, and J. M. Hallen, Appl. Surf. Sci., 252, 2894 (2006).

54. J. L. Endrino, J. F. Marco, M. Allen, P. Poolcharuausin, A. R. Phani, J. M. Albella, and A. Anders, Appl. Surf. Sci., 254, 5323 (2008).

55. A. D. Ryabov, Angew. Chem., Int. Ed. Engl., 30, 931 (1991).

56. J.-S. Wu, K. Toda, A. Tanaka, and I. Sanemasa, Bulletin of the Chemical Society of Japan, 71, 1615 (1998).

57. E. M. Garrido, J. L. Costa Lima, C. M. Delerue-Matos, and A. M. Oliveira Brett, Talanta, 46, 1131 (1998)

58. C. Yáñez, P. Cañete-Rosales, J. P. Castillo, N. Catalán, T. Undabeytia, and E. Morillo, PLoS One, 7, e41072 (2012).

59. J. A. Porini and G. M. Escandar, Analytical Methods, 3, 1494 (2011).

60. S. Jevtića, A. Stefanovića, D. M. Stankovićb, M. V. Pergal, A. T. Ivanović, A. Jokić, and B. B. Petković, Diam. Relat. Mater, 81, 133 (2018).

61. C. Yañez, M. Araya, and S. Bollo, J. Inclusion Phenom. Macrocycl. Chem., 68, 237 (2010). 